\title{
Modeling the impact of chlorine emissions from coal combustion and pre- scribed waste incineration on tropospheric ozone formation in China
}

Yiming Liu et al.

Correspondence to: Qi Fan (eesfq@mail.sysu.edu.cn) and Jun Zhao (zhaojun23@mail.sysu.edu.cn)

The copyright of individual parts of the supplement might differ from the CC BY 4.0 License. 

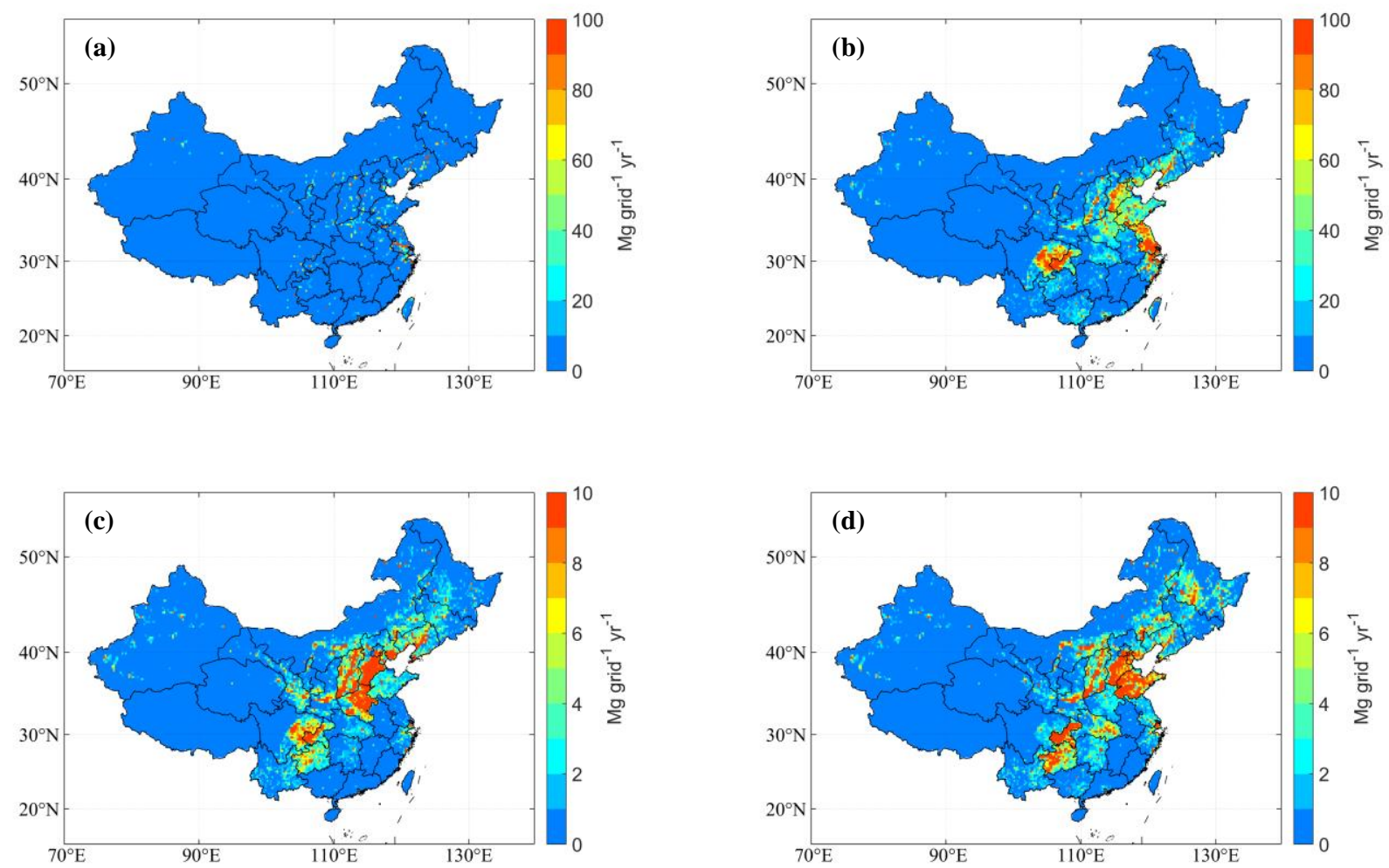

Figure S1 Spatial distribution of hydrogen chloride emission from coal combustion in four economic sectors: power plant (a), industry (b), residential (c) and other (d). 

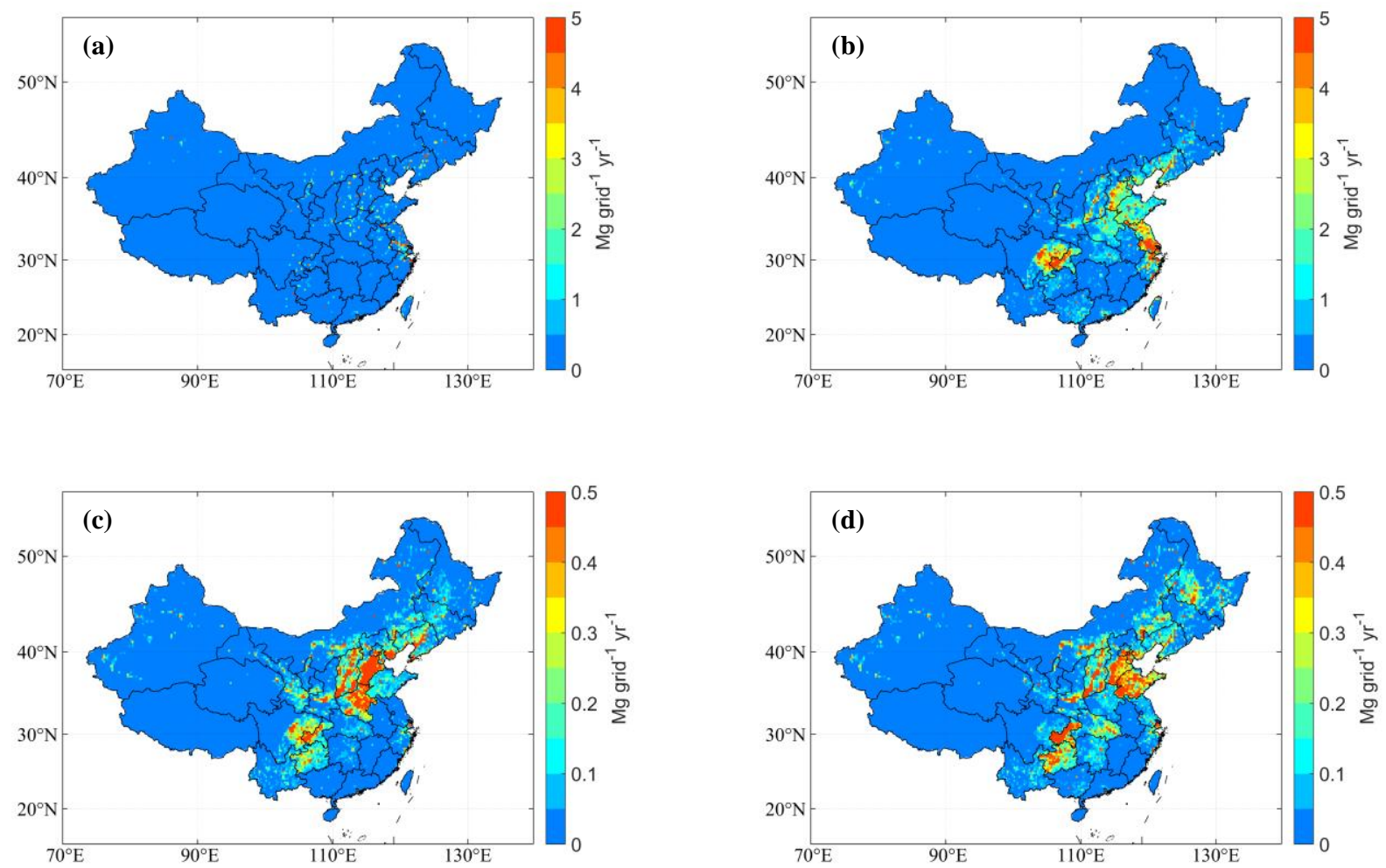

Figure S2 Spatial distribution of molecular chlorine emission from coal combustion in four economic sectors: power plant (a), industry (b), residential (c) and other (d).

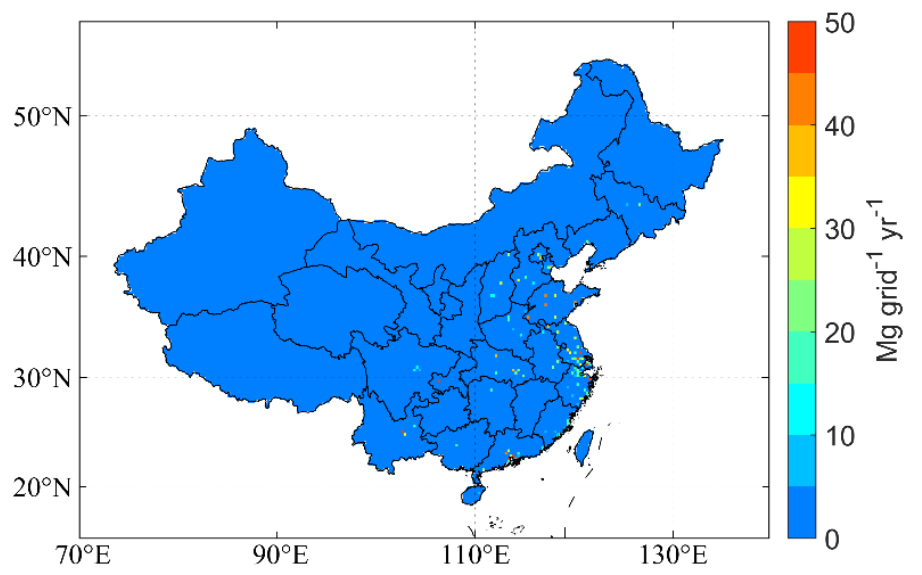

Figure S3 Spatial distribution of hydrogen chloride emission from prescribed waste incineration in 2012. 

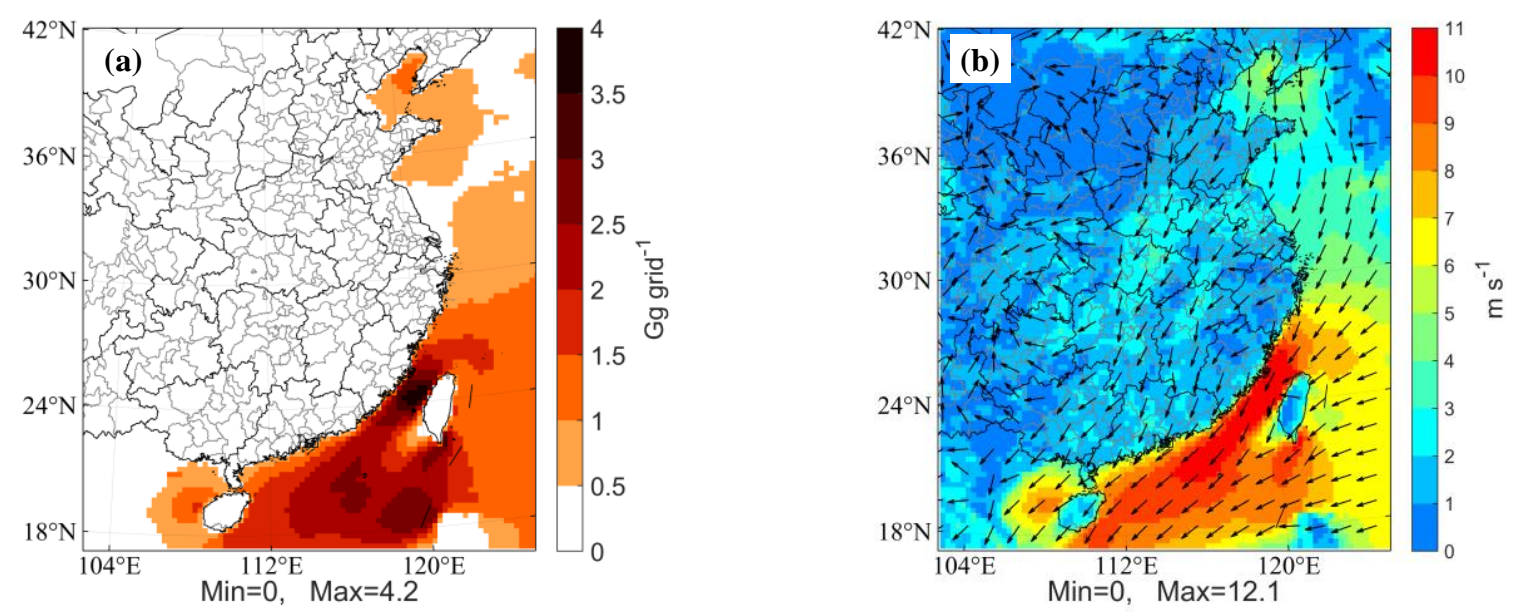

Figure S4 Spatial distributions of dry sea salt emission (a) and wind vector (b) in November 2011. Dry sea salt includes particulate $\mathrm{Cl}^{-}, \mathrm{SO}_{4}{ }^{2-}, \mathrm{Na}^{+}, \mathrm{Mg}^{2+}, \mathrm{K}^{+}$and $\mathrm{Ca}^{2+}$ in coarse and fine mode. High sea salt emission was found in South China Sea due to the high wind speed over sea.

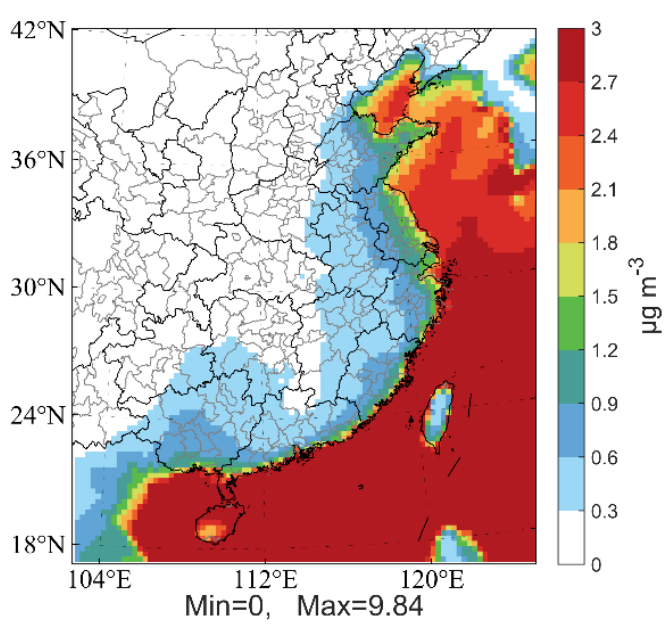

Figure S5 Spatial distribution of the monthly mean concentration of coarse particulate $\mathrm{Na}^{+}$. Coarse particulate $\mathrm{Na}^{+}$is the important composition in sea salt aerosol and is considered to be inactive. This figure can reflect the impact of sea salt aerosol over land. 


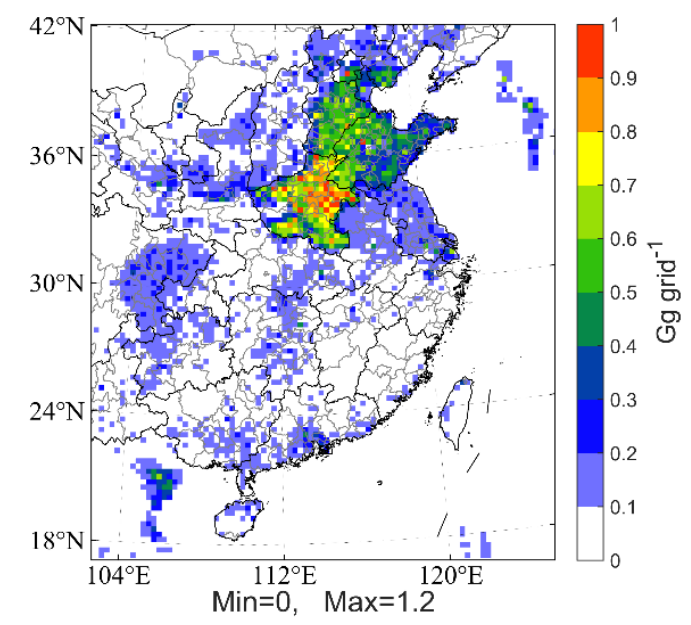

Figure S6 Spatial distribution of the $\mathrm{NH}_{3}$ emission in November in the MIX emission inventory.

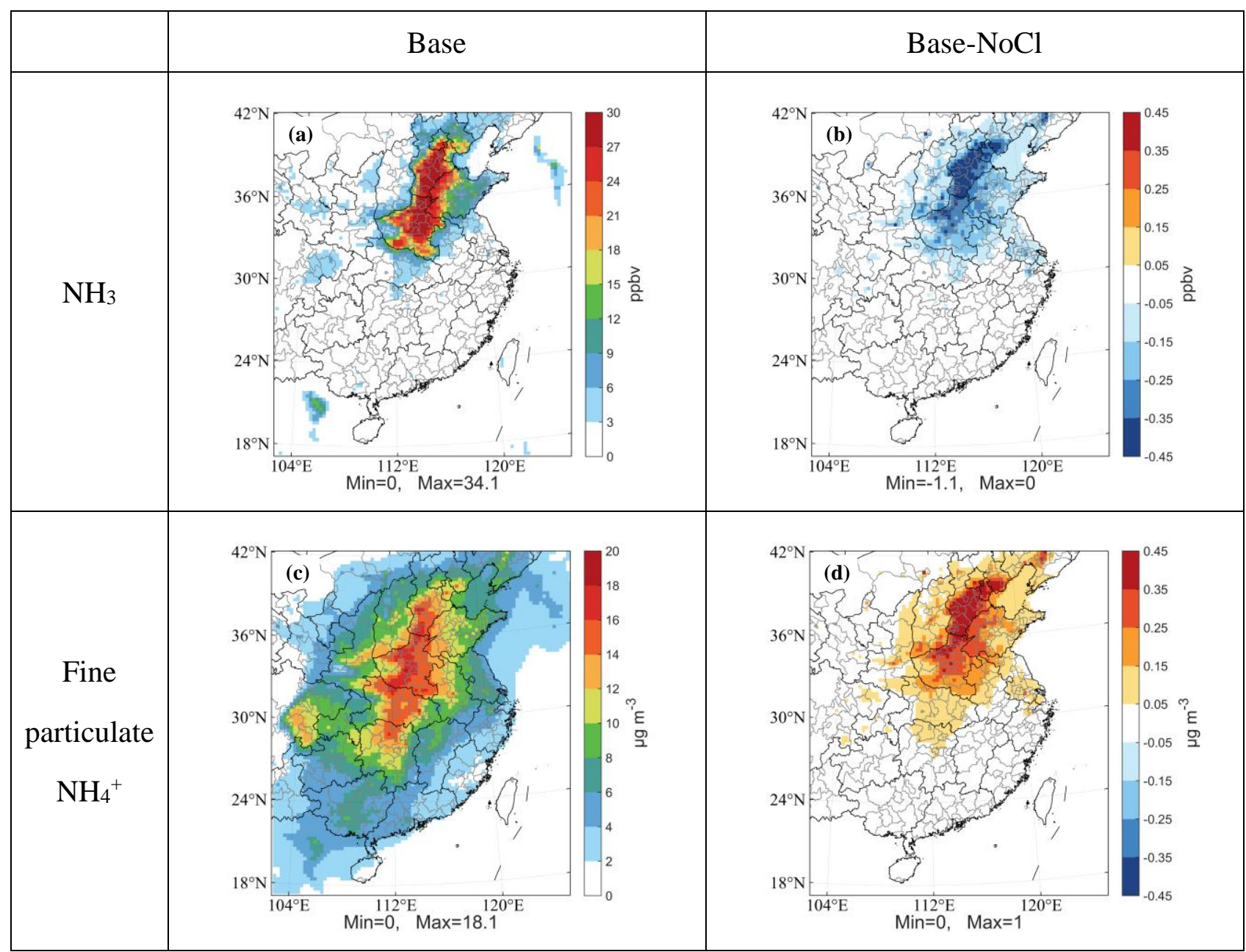

Figure S7 Spatial distributions of the monthly mean concentrations of $\mathrm{NH}_{3}$ and fine particulate $\mathrm{NH}_{4}{ }^{+}$in the Base experiment and the differences (Base minus $\mathrm{NoCl}$ ). 


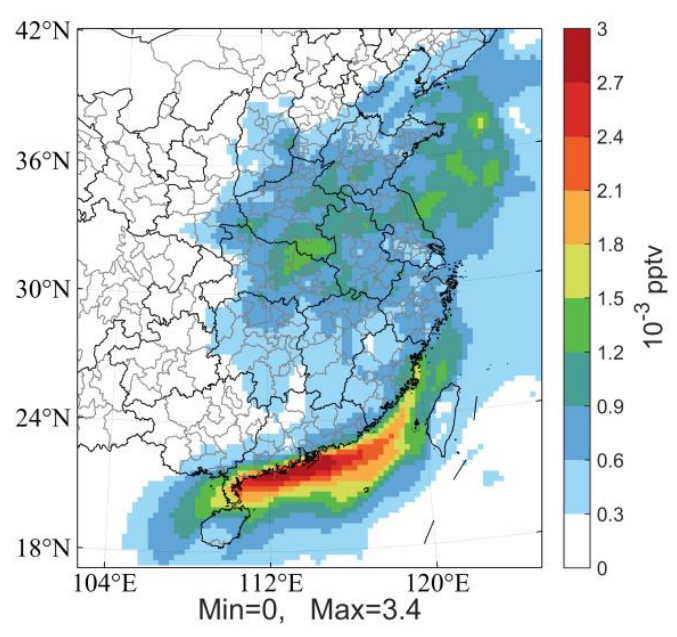

Figure S8 Spatial distribution of the monthly mean $\mathrm{Cl}_{2}$ concentration in the $\mathrm{NoCl}$ experiment.

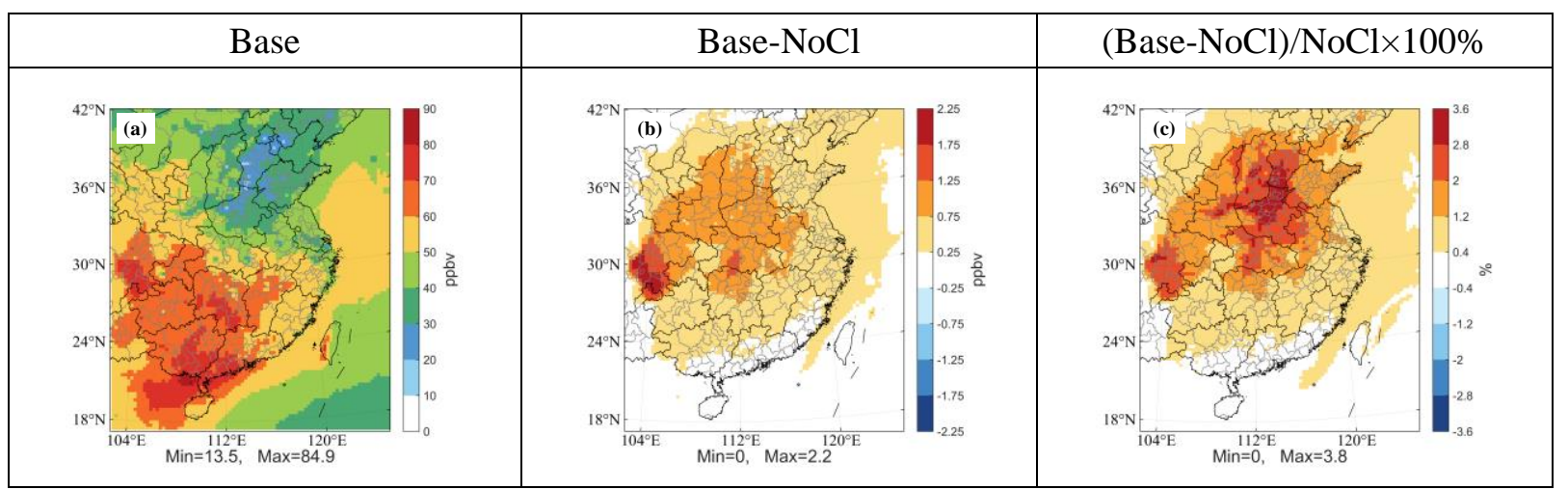

Figure S9 Spatial distributions of the monthly mean concentrations of daily maximum $1-\mathrm{h} \mathrm{O}_{3}$ in the Base experiment, the differences (Base minus $\mathrm{NoCl}$ ), and the percent changes of the Base experiment to the $\mathrm{NoCl}$ experiment. 